\title{
The Association Between Oxidative Stress, Inflammation and Diabetes
}

\author{
Sharon Hall Murff* \\ Department of Nursing, Grambling State University, USA \\ *Corresponding author: Sharon Hall Murff, Department of Nursing, Grambling State University, USA. \\ To Cite This Article: Sharon Hall Murff. The Association Between Oxidative Stress, Inflammation and Diabetes. Am J Biomed Sci \& Res. 2019 - \\ 4(1). AJBSR.MS.ID.000755. DOI: 10.34297/AJBSR.2019.04.000755
}

Received: July 04, 2019 | Published: July 16, 2019

\section{Opinion}

The concept of stress has been studied over many decades. An individual can research various forms of stress such as psychological, physiological, emotional, acute, and chronic. Other terms related to stress are daily hassles and oxidative. Holmes \& Rahe [1] and Selye [2] reported that stress is a force or, are forces that place demands on an individual and as a result a series of responses occur. Selye [2] also reported that the forces, also termed stressors, evoke positive or negative responses in an individual. The aim of this manuscript is to describe the association between oxidative stress and diabetes mellitus. Diabetes mellitus (DM) is a disorder related to impairment in glucose metabolism. In 2013 a report from the World Health Organization (WHO) indicated that globally, the number of people with chronic diseases such as diabetes was increased [3]. The world-wide mortality rate for people with diabetes and other chronic diseases (i.e. cardiovascular and renal diseases) has been estimated to be greater than $60 \%$ [4]. Predictions related to the global prevalence of diabetes are that by the year 2030 over 400 million people will have diabetes. He et al. [5] reported an association between chronic diseases, inflammation, and stress, more namely, oxidative stress.

The concept of chronicity refers to a long duration with respect to time [6]. Therefore, a chronic disease indicates that it has occurred for a long period of time. Kanner et al. [7] reported that stress experienced over a long period of time can cause damage to the body. Also, when an individual experiences chronic stress, the inflammatory response is activated [5]. Various chemical mediators are released during the inflammatory process. For example, alteration of mast cells causes a release of histamine, and together with other chemicals such as tumor necrosis factor alpha and interleukin 6 (IL-6), the inflammatory process is amplified [8]. Howcroft et al. [9] indicated that during the inflammatory response, not only are biomarkers such as IL-18 and C-reactive protein (CRP) released, but in response to chronic inflammation, tissue damage can occur. Oxidative stress is a process that occurs when there are high levels of free radicals that are formed. In other words, disequilibrium exists between an increase in free radicals, also known as reactive oxygen species (ROS), and the antioxidant mechanisms of the body (Betteridge, 2000). A connection between oxidative stress and diabetes has been identified [10]. People with diabetes often experience high levels of glucose (hyperglycemia), and as a result of oxidation of the glucose molecule, free radicals can proliferate [11]. An imbalance in biomarkers associated with oxidative stress, such as superoxide dismutase, catalase, and glutathione reductase can result in development of diabetes and complications associated with diabetes.

The danger associated with diabetes, oxidative stress, and the production of free radicals is that damaging complications can ensue. Maritim et al. [11] reported that an imbalance in vitamins A, C, and E can lead to complications associated with diabetes. Also, an increase in the formation of nitric oxide has also been associated with complications of diabetes. Microvascular complications associated with diabetes include diabetic retinopathy, renal disease, and damage to the peripheral nerves in the hands and feet which can result in amputation of the limbs [12]. On the other hand, macrovascular complications relate to disorders of the heart, brain, and the peripheral vascular system (ADA, 2017). Because of the increase morbidity and mortality associated with diabetes (ADA, 2017), healthcare expenditures have increased [13,14]. In order to achieve positive outcomes related to care of people with diabetes it is imperative to study the factors responsible for the development of the disease and its' complications. Since diabetes is so widespread, it is important that researchers continue the quest into the relationship between oxidative stress, inflammation, and diabetes. Also, researchers and healthcare professionals can introduce beneficial therapies for the management of the complex disease of diabetes.

\section{References}

1. Holmes T, Rahe R (1967) The social readjustment rating scale. Journal of Psychosomatic Research 11(2): 213-218.

2. Selye H (1976) The stress of life. McGraw-Hill, New York, USA.

3. Guariguata L, Whiting DR, Hambleton I, Beagley J, Linnenkamp U, et al. (2014) Global estimates of diabetes prevalence for 2013 and projections for 2035. Diabetes Res Clin Pract 103(2): 137-149. 
4. Harris RE (2013) Epidemiology of chronic disease: Global perspectives. Jones \& Barlett Learning, Burlington, Massachusetts , USA.

5. He Y, Yue Y, Zheng X, Zhang K, Chen S, et al. (2015) Curcumin, inflammation, and chronic diseases: How are they linked? Molecules 20(5): 9183-9213.

6. Webster M (2002) Webster's New World Dictionary and Thesaurus ( $2^{\text {nd }}$ edition), Wiley Publishing Inc, Cleveland, Ohio, USA.

7. Kanner AD, Coyne JC, Schafer C, Lazarus RS (1981) Comparison of two modes of stress measurement: Daily hassles and uplifts versus major life events. J Behav Med 4(4): 1-39.

8. Huether SE, Mc Cance KL (2012) Understanding pathophysiology $5^{\text {th }}$ edition. Elsevier Mosby, USA.

9. Howcroft TK, Campisi J, Louis G B, Smith MT, Wise B, et al. (2013) The role of inflammation in age-related disease. Aging (Albany NY) 5(1): 8493.
10. Maiese K (2015) New Insights for Oxidative Stress and Diabetes Mellitus. Oxid Med Cell Longev pp. 875961.

11. Maritim AC, Sanders RA, Watkins JB (2003) Diabetes, oxidative stress, and antioxidants: a review. J Biochem Mol Toxicol 17(1): 24-38.

12. ADA (2017) Overall Numbers, Diabetes and Prediabetes. Statistics About Diabetes.

13. CDC (2014) National diabetes statistics report: Estimates of diabetes and its burden in the United States.

14. Tiwari BK, Pandey KB, Abidi AB, Rizvi SI (2013) Markers of oxidative stress during diabetes mellitus. Journal of Biomarker pp. 378790. 